\title{
Flame Spread Evaluation for Thin Interior Finish Materials
}

\author{
FREDERICK W. MOWRER \\ University of Maryland \\ College Park, Maryland 20742, USA \\ ROBERT BRADY WILLIAMSON \\ University of California \\ Berkeley, California 94720, USA
}

\begin{abstract}
A simplified model of flame spread that includes consideration of fuel burnout is applied to the evaluation of upward flame spread on thin lining materials adhered to noncombustible substrates. A flammability parameter based on characteristic unit heat release rates, flame spread times and burning durations is derived. Methods to evaluate this flammability parameter from small-scale heat release rate measurements in the Cone Calorimeter are developed. Comparisons between predictions and large-scale $\mathrm{room} /$ corner fire tests for a number of textile wallcovering materials are presented.
\end{abstract}

Keywords: Flame spread, heat release, ignition time, burning duration, interior finish.

\section{INTRODUCTION}

Building regulations traditionally have restricted the application of interior finish materials on the basis of flame spread characteristics. A number of classification schemes based on various small- to medium-scale fire tests have been developed in different countries to implement these restrictions. In the United States all the Model Building Codes [1] use ASTM E84 Tunnel Test [2] results to rank finish materials into four flammability classifications: Class I or A, Class II or B, Class III or C, and Class IV or D. Permitted applications of finish materials are based on these classifications and depend on the use or occupancy of a building as well as on the location within a building. In general, vertical exitways require Class A ratings, while horizontal exitways, such as corridors, require Class B ratings. Most occupied spaces may have Class C ratings. With few exceptions, finishes with Class $D$ ratings are prohibited everywhere. A literal interpretation of ASTM E84 Tunnel Test results suggests that the four flammability classifications can be considered to imply the following qualitative flame spread characteristics: 
Class A: Products that will not spread an incipient fire beyond the vicinity of origin.

Class B: Products that may spread a fire at a relatively slow rate.

Class $\mathrm{C}$ : Products that may spread a fire at moderate to relatively fast rates.

Class D: Products that are expected to spread a fire at unacceptably rapid rates.

This type of classification system was judged as providing an acceptable level of public safety when it was implemented in the 1940s to 1950 s, a period when cellulosic fuels dominated the built environment. With the widespread introduction of synthetic finish materials, notably foam plastic insulation products and textile wall coverings, in the 1960 s and 1970s, however, anomalous behavior was observed. Some products could obtain Class A ratings based on the Tunnel Test, but would produce rapid flame spread and flashover when evaluated in room/corner fire tests.

The potential for propagating flame spread (ie., Class B-D behavior) versus localized fuel burnout (ie., Class A behavior) depends on a balance between the rate at which new fuel is heated to ignition, the rate at which burning fuel is consumed and the amount of fuel available for combustion. In this paper, a simplified model of upward flame spread that considers fuel burnout is applied to the evaluation of flame spread over thin wall covering materials adhered to noncombustible substrates. For applications where Class A performance is desired, the fundamental question is whether an interior finish material will propagate a fire under specified large-scale exposure conditions or will simply burn out in the vicinity of the exposure fire. The primary goal here is to determine if this simplified model can be used for screening purposes in conjunction with small-scale heat release rate measurements to evaluate the expected performance of interior finish materials.

\section{THEORETICAL CONSIDERATIONS}

An approach to modeling upward flame spread developed by Quintiere, et al. [3], is used here to identify the key parameters controlling the flame spread process. This model includes consideration of fuel burnout, an important aspect of the flame spread process over relatively thin fuels such as textile wallcoverings. The general concept of the model and some of the variables used in the model are illustrated in Fig. 1.

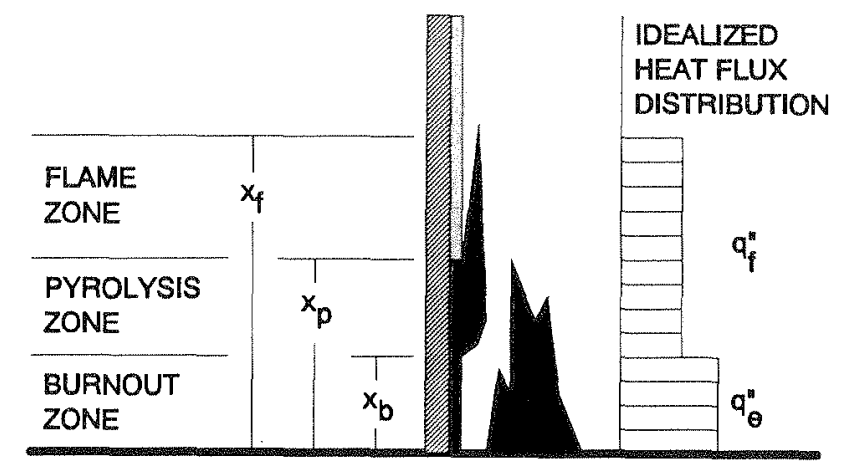

FIGURE 1. Schematic illustration of the upward flame spread model. 
In this model, the flame spread rate is defined as the rate of pyrolysis front advance:

$$
V_{p}=\frac{d x_{p}}{d t} \cong \frac{x_{p}\left(t+t_{f}\right)-x_{p}(t)}{t_{f}}=\frac{x_{f}(t)-x_{p}(t)}{t_{f}}
$$

The characteristic flame spread time is defined in terms of a thermal model of heating an inert wall with constant properties [4]:

$$
t_{f} \underline{\underline{k}} k \rho\left[\left(T_{\dot{i g}}-T_{S}\right) / \dot{q}^{\prime \prime}\right]^{2}
$$

The heat flux imposed by the external ignition source is considered to be constant in the vicinity of the exposure fire and zero elsewhere. Based on measurements by Williamson, et al. [5], external heat fluxes of approximately 50 to $60 \mathrm{~kW} / \mathrm{m}^{2}$ are representative for the room fire tests considered here. Similarly, the heat flux imposed by the wall flame is treated as constant, with a value of approximately 25 to $30 \mathrm{~kW} / \mathrm{m}^{2}$ [6], in the pyrolysis and flame zones and zero elsewhere. Once the wall fuel in the vicinity of the external ignition source burns out, additional wall fuel is considered to be exposed only to the wall flame heat flux.

Once burnout commences, the rate of fuel burnout can be expressed as:

$$
v_{b}=\frac{d x_{b}}{d t} \approx \frac{x_{b}\left(t+t_{b o}\right)-x_{b}(t)}{t_{b o}}=\frac{x_{p}(t)-x_{b}(t)}{t_{b o}}
$$

A linearized flame length approximation is used, following Quintiere, et al. [3], Saito, et al. [7], and Cleary and Quintiere [8]. Before burnout commences, this flame length approximation can be expressed as:

$$
\frac{x_{f}}{x_{p}}=k_{f} \dot{E}^{\prime \prime}
$$

After burnout begins, the dimensionless flame length is expressed as:

$$
\frac{\left(x_{f}-x_{b}\right)}{\left(x_{p}-x_{b}\right)}=k_{f} \dot{E}^{\prime \prime}
$$

The parameter $\mathrm{k}_{\mathrm{f}}$ is a correlating factor used to define the flame length ahead of the pyrolysis zone. Cleary and Quintiere [8] suggest a value of approximately $0.01 \mathrm{~m}^{2} / \mathrm{kW}$ for $k_{f}$. Using Equation 4 for times $t<t_{b}$, Equation 1 can be rewritten as:

$$
\frac{d x_{p}}{d t}=\left(k_{f} \dot{E}^{\prime \prime}-1\right) \frac{x_{p}}{t_{f}}
$$

Equation 6 can be integrated, with the limits that $x=x_{p o}$ at $t=0$ and $x=x_{p}$ at $t=t$ :

$$
x_{p}=x_{p o} \exp \left[\left(k_{f} \dot{E}^{\prime \prime}-1\right) t / t_{f}\right]
$$

Equations 6 and 7 together with Equation 4 suggest that, before burnout, the flame spread rate will be acceleratory if $x_{f}>x_{p}$ and deceleratory if $x_{f}<x_{p}$, ie.; if $k_{f} \dot{E}^{\prime \prime}<1$. 
After burnout begins, at times $t>t_{b}$, the net rate of flame propagation can be expressed as the difference between the pyrolysis front velocity and the burnout front velocity:

$$
V_{p}(t)-V_{b}(t)=\frac{d}{d t}\left(x_{p}-x_{b}\right)=\frac{\left(x_{f}-x_{p}\right)}{t_{f}}-\frac{\left(x_{p}-x_{b}\right)}{t_{b o}}
$$

Using Equation 5, Equation 8 can be rearranged to:

$$
\frac{d}{d t}\left(x_{p}-x_{b}\right)=\left(x_{p}-x_{b}\right)\left[\frac{\left(k_{f} \dot{E}^{\prime \prime}-1\right) t_{b o}-t_{f}}{t_{f} t_{b o}}\right]
$$

Equation 9 can then be integrated, with the limits of $\left(x_{\mathrm{p}}-\mathrm{x}_{\mathrm{b}}\right)=\left(\mathrm{x}_{\mathrm{p} 1}-\mathrm{x}_{\mathrm{po}}\right)$ at $\mathrm{t}=\mathrm{t}_{\mathrm{b}}$ and $\left(\mathrm{x}_{\mathrm{p}}-\right.$ $\left.x_{b}\right)=\left(x_{p}-x_{b}\right)$ at time $t=t$, to yield the pyrolysis zone length at any time:

$$
\left(x_{p}-x_{b}\right)=\left(x_{p 1}-x_{p o}\right) \exp \left[\left(k_{f} \dot{E}^{\prime \prime}-t_{f} / t_{b o}-1\right)\left(t-t_{b}\right) / t_{f}\right]
$$

Equation 10 suggests that, following the onset of fuel burnout, the potential for acceleratory spread depends on a balance among three parameters: the normalized flame length, $\left(x_{\mathrm{f}}-\mathrm{x}_{\mathrm{b}}\right) /\left(\mathrm{x}_{\mathrm{p}}-\mathrm{x}_{\mathrm{b}}\right)$, which is represented per Equation 5 as a linear function of the unit heat release rate, $\dot{E}$ ", the flame spread time, $t_{f}$, given by Equation 2, and the burning duration, $t_{b o}$. If the parameter $\left(k_{f} \dot{E}^{n-} t_{f} / t_{b o}\right)>1$, acceleratory spread is predicted.

\section{MEASUREMENT OF FLAMMABHLITY PARAMETERS}

The three flammability parameters, $\dot{\mathrm{E}}^{\prime \prime}, \mathrm{t}_{\mathrm{f}}$ and $\mathrm{t}_{\mathrm{bo}}$, can be evaluated directly in the Cone Calorimeter [9] or other small-scale heat release rate calorimeters. These parameters are identified in Fig. 2, which shows representative heat release rate curves derived from Cone Calorimeter measurements for two textile wallcovering materials adhered to gypsum wallboard. Fig. $2 \mathrm{a}$ is representative of products with distinct growth and decay curves, while Fig. $2 \mathrm{~b}$ is representative of products with longer burning durations.
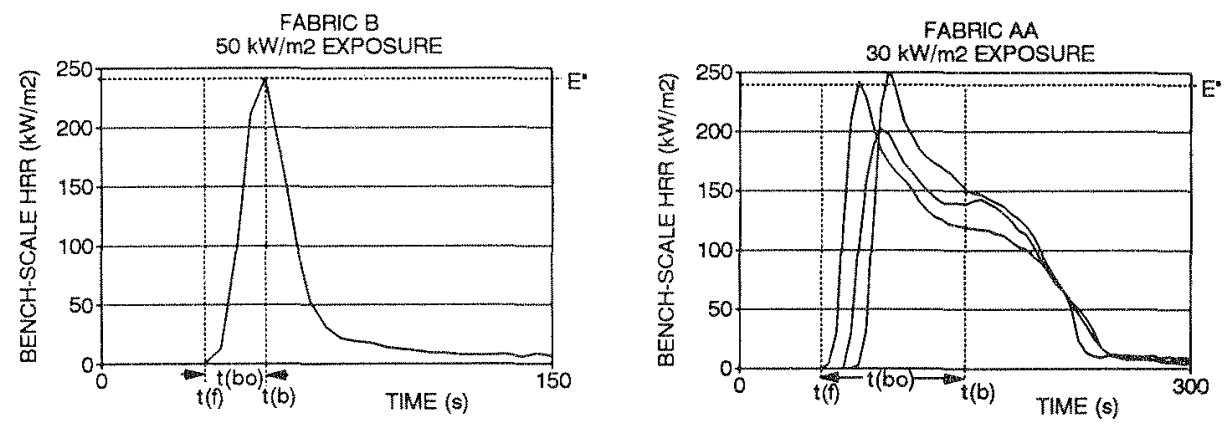

FIGURE 2. Cone Calorimeter heat release rate curves [13]. a) Fabric B; b) Fabric AA 
The unit heat release rate, $\dot{\mathrm{E}}^{\prime \prime}$, is taken as the peak measured heat release rate for the purpose of this analysis. This will yield the most conservative estimate of flame propagation potential. Where multiple tests have been made, as illustrated in Fig. 2b, the peak heat release rate associated with the shortest flame spread time has been used. The flame spread time, $t_{f}$, is measured directly in the Cone Calorimeter as the time when the test specimen ignites under the imposed heat flux. In general, the burning duration, $\mathfrak{t}_{\mathrm{bo}}$, is calculated from test data as:

$$
t_{b o}=E^{\prime \prime} / E^{\prime \prime}
$$

where $E^{\prime \prime}$ is the total energy released during the test. For cases with distinct growth and decay curves, such as shown in Fig. $2 \mathrm{a}$, the burning duration is approximately the time from ignition to the time of peak heat release rate. The three flammability parameters are all functions of the heat flux at the fuel surface, so separate evaluations can be made at a number of different imposed heat fluxes. Implications of different imposed heat fluxes are discussed below.

Harkleroad [10] has made energy release rate and ignition measurements in the Cone Calorimeter for ten textile wall covering materials, including woven, knit and needle punched polyesters, woven cotton/rayon and wool/nylon blends, nylon and polypropylene products. The Cone Calorimeter was operated to produce imposed heat fluxes of 30 and $50 \mathrm{~kW} / \mathrm{m}^{2}$ at the test specimen surface. These ten materials were among a larger number of textile wallcoverings Fisher, et al. [11] had previously tested at largescale in the room/corner fire test facility at the University of California, Berkeley.

The flammability parameters derived from Cone Calorimeter test results for these ten wall covering materials are tabulated in Table 1, along with the peak heat release rates measured in the large-scale tests at the University of California, Berkeley. For some of these large-scale screening tests, one-foot wide test specimens were attached to the corner behind the ignition source and along the walls at the wall/ceiling intersection. For later tests, two-foot wide strips were used. Results are tabulated separately in Table 1 based on test specimen width.

TABLE 1. Measured and calculated flammability parameters

\begin{tabular}{|c|c|c|c|c|c|c|c|c|c|c|c|}
\hline \multirow{4}{*}{ FABRIC } & \multicolumn{6}{|c|}{ CONE CALORIMETER RESULTS } & \multirow{2}{*}{\multicolumn{3}{|c|}{$\begin{array}{c}k E^{n}-t(f) / t(b o) \\
k=0.01 ; t(b o)=t(b)-t(f)\end{array}$}} & \multirow{2}{*}{\multicolumn{2}{|c|}{$\begin{array}{c}\text { LARGE-SCALE } \\
\text { PEAK HRR }\end{array}$}} \\
\hline & \multicolumn{3}{|c|}{$30 \mathrm{~kW} / \mathrm{m} 2$ EXPOSURE } & \multicolumn{3}{|c|}{$50 \mathrm{~kW} / \mathrm{m} 2 \mathrm{EXPOSURE}$} & & & & & \\
\hline & $t(f)$ & $t(b)$ & $\mathrm{E}^{n}$ & $t(f)$ & $t(b)$ & $E^{*}$ & $30 \mathrm{~kW} / \mathrm{m}^{2}$ & $50 \mathrm{~kW} / \mathrm{m}^{2}$ & COMBINED & $1 \mathrm{FOOT}$ & $2 \mathrm{FOOT}$ \\
\hline & (s) & (s) & $\mathrm{kW} / \mathrm{m} 2$ & (s) & (s) & $\mathrm{kW} / \mathrm{m} 2$ & - &. & - & $\mathrm{kW}$ & $k W$ \\
\hline $\mathrm{Q}$ & 175 & 188 & 165 & 33 & 50 & 265 & .11 .81 & 0.71 & -7.64 & 207 & 497 \\
\hline$\overline{Q-F R}$ & 192 & 205 & 219 & 33 & 65 & 230 & .12 .58 & 1.27 & -3.70 & 310 & \\
\hline $\mathrm{B}$ & 168 & 180 & 156 & 34 & 55 & 249 & -12.44 & 0.87 & -5.51 & 207 & 298 \\
\hline $\mathrm{G}$ & 230 & 240 & 85 & 19 & 35 & 83 & -22.15 & -0.36 & -13.55 & 83 & \\
\hline $\mathrm{C} 2^{2}$ & 85 & 100 & 119 & 34 & 55 & 135 & -4.48 & .0 .27 & .2 .70 & 62 & 119 \\
\hline $\mathrm{Cl}$ & 80 & 95 & 130 & 25 & 45 & 140 & -4.03 & 0.15 & -2.60 & & \\
\hline $\mathrm{R}$ & 35 & 65 & 70 & 25 & 55 & 340 & -0.47 & 2.57 & 2.23 & 587 & 590 \\
\hline$\overline{\mathrm{AA}}$ & 60 & 150 & 242 & 16 & 130 & 225 & 1.75 & 2.11 & 1.72 & 684 & \\
\hline PP-PF & 80 & 120 & 217 & 29 & 65 & 286 & 0.17 & 2.05 & 0.64 & & 1166 \\
\hline $\mathrm{H}$ & - & - & - & 20 & 40 & 170 & - & 0.70 & - & 46 & 160 \\
\hline
\end{tabular}




\section{RESULTS}

Values of the calculated flammability parameter, $\left(\mathrm{k} \dot{E}^{\prime \prime}-t_{f} / t_{b o}\right)$, for each of the fabrics tested in small scale are tabulated in Table 1. Separate values have been calculated for the two imposed heat fluxes of 30 and $50 \mathrm{~kW} / \mathrm{m}^{2}$. A third value, under the column labeled "COMBINED", uses data derived from both the 30 and $50 \mathrm{~kW} / \mathrm{m}^{2}$ exposures for reasons discussed below. For these calculations, $\mathrm{k}_{\mathrm{f}}=0.01 \mathrm{~m}^{2} / \mathrm{kW}$ has been used.

The flammability parameter under the "COMBINED" column was calculated using the energy release rate, $E^{\prime \prime}$, and the burning duration time, $t_{b o}=t_{b}-t_{f}$, from the $50 \mathrm{~kW} / \mathrm{m}^{2}$ exposure and the flame spread time, $\mathrm{t}_{\mathrm{f}}$, from the $30 \mathrm{~kW} / \mathrm{m}^{2}$ exposure. This is justified on the following basis. In the large-scale room/corner tests, the exposure fire produces peak heat fluxes in the range of 50 to $60 \mathrm{~kW} / \mathrm{m}^{2}$ at the test specimen surface [5]. Beyond the zone of initial pyrolysis, $\mathrm{x}_{\mathrm{po}}$, exposed to this high incident heat flux, the fuel will be exposed primarily to the heat flux produced by the wall flame. Heat fluxes from wall flames have been measured in the range of 25 to $30 \mathrm{~kW} / \mathrm{m}^{2}[6]$. This would be the approximate heat flux exposing fuel in the flame zone ahead of the pyrolysis front. Thus, the original pyrolysis zone, $x_{\mathrm{po}}$, is considered to burn with an intensity, $\mathrm{E}^{\prime \prime}$, and for a duration, $t_{b o}$, associated with a $50 \mathrm{~kW} / \mathrm{m}^{2}$ heat flux, while the material ahead of the pyrolysis zone is considered to be exposed to a wall flame heat flux of approximately $30 \mathrm{~kW} / \mathrm{m}^{2}$.

Fig. 3 a shows the peak heat release rate in large scale versus the bench scale peak heat release rate at an imposed heat flux of $30 \mathrm{~kW} / \mathrm{m}^{2}$. Fig. $3 \mathrm{~b}$ shows the same data for an imposed heat flux of $50 \mathrm{~kW} / \mathrm{m}^{2}$ in the Cone Calorimeter. Peak heat release rates measured in large-scale are plotted against the flammability parameter $\left(\mathrm{k} \dot{\mathrm{E}} "-\mathrm{t}_{\mathrm{f}} / \mathrm{t}_{\mathrm{bo}}\right)$ in Fig. 4. Fig. 4 a shows results for the $30 \mathrm{~kW} / \mathrm{m}^{2}$ imposed heat flux, Fig. $4 \mathrm{~b}$ for the 50 $\mathrm{kW} / \mathrm{m}^{2}$ flux and Fig. $4 \mathrm{c}$ for the "COMBINED" parameter discussed above.
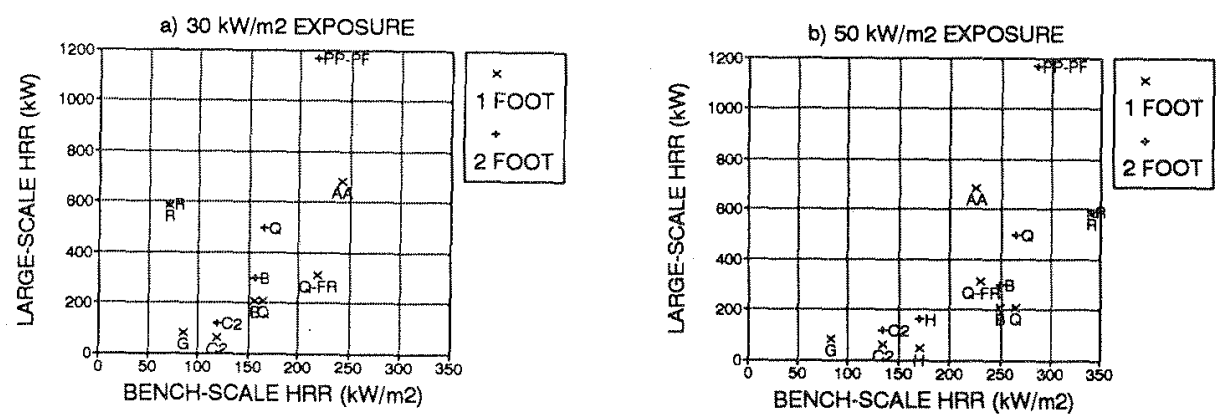

FIGURE 3. Large-scale peak heat release rate versus Cone Calorimeter peak heat release rate for (a) $30 \mathrm{~kW} / \mathrm{m}^{2}$ imposed heat flux; (b) $50 \mathrm{~kW} / \mathrm{m}^{2}$ imposed heat flux. 
a) $30 \mathrm{~kW} / \mathrm{m} 2 \mathrm{EXPOSURE}$

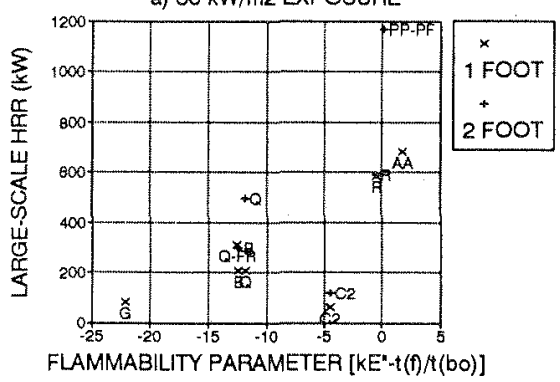

FIGURE 4. Large-scale peak heat release rate versus flammability parameter for (a) $30 \mathrm{~kW} / \mathrm{m}^{2}$ imposed heat flux; (b) $50 \mathrm{~kW} / \mathrm{m}^{2}$ imposed heat flux; (c) combined $30 / 50 \mathrm{~kW} / \mathrm{m}^{2}$ imposed heat flux. b) $50 \mathrm{~kW} / \mathrm{m} 2$ EXPOSURE

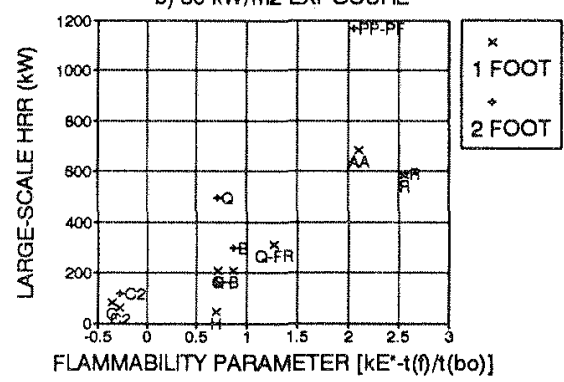

c) COMBINED $30 / 50 \mathrm{~kW} / \mathrm{m} 2$ EXPOSURE

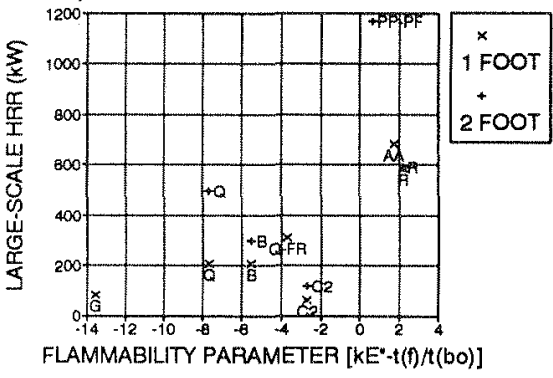

\section{DISCUSSION}

Based on the large-scale screening tests of Fisher, et al. [11], Belles, et al. [12] observed that a test specimen which produced a peak heat release rate of $300 \mathrm{~kW}$ or less would not cause a fire to grow to flashover, while one that produced a peak in excess of 500 $\mathrm{kW}$ would likely cause flashover. Intermediate values would require further evaluation. These observations are used here as the basis for evaluating fire propagation propensity.

A simple correlation between peak bench-scale heat release rate and large-scale performance is not apparent in Figs. $3 \mathrm{a}$ and $3 \mathrm{~b}$. Fabric $\mathrm{R}$ would clearly produce misleading results based only on peak heat release rate at a heat flux of $30 \mathrm{~kW} / \mathrm{m}^{2}$ in the Cone Calorimeter, while relatively small differences in the small-scale behavior of Fabrics PP-PF and Q-FR would appear to be inconsistent with the four-fold difference in large-scale performance.

Using the flammability parameter $\left(\mathrm{kE} "-t_{f} / t_{b o}\right)$ in place of the bench-scale heat release rate alone yields results that depend on the exposure conditions used to calculate the flammability parameter. Three cases are considered here: use of just the $30 \mathrm{~kW} / \mathrm{m}^{2}$ exposure data, use of just the $50 \mathrm{~kW} / \mathrm{m}^{2}$ exposure data and use of combined data from both the 30 and the $50 \mathrm{~kW} / \mathrm{m}^{2}$ exposures in the manner described above.

The data for the $30 \mathrm{~kW} / \mathrm{m}^{2}$ exposure level, shown in Fig. 4a, demonstrates the general trend apparent for all three cases considered. The three fabrics with the highest flammability parameter values were the three fabrics that demonstrated a propensity for 
flame spread in the large scale room fire tests. At this heat flux, these three fabrics had flammability parameters ranging from -0.5 to 1.75 , while all the nonpropagating fabrics had flammability parameters of less than -4 at this imposed heat flux. Thus, at this heat flux, the calculated flammability parameters seem to demonstrate trends consistent with large scale performance, but the absolute values of the flammability parameter are not quite correct in terms of the simplified model.

The flammability parameters calculated from the data for the $50 \mathrm{~kW} / \mathrm{m}^{2}$ exposure level demonstrate the same general trends as the $30 \mathrm{~kW} / \mathrm{m}^{2}$ data, as shown in Fig. $4 \mathrm{~b}$. Again, the three propagating fabrics demonstrate the highest flammability parameters, with all values between 2 and 2.6. Calculating the flammability parameter on the basis of the $50 \mathrm{~kW} / \mathrm{m}^{2}$ exposure tends to compress the data. All of the nonpropagating materials have calculated flammability parameters between -0.4 and 1.3 at this heat flux. Fabric Q-FR, with a large scale heat release rate of $310 \mathrm{~kW}$ and a calculated flammability parameter of 1.3 , appears to be a material on the verge of critical propagation. Three other nonpropagating materials, with flammability parameters between 0.7 and 0.9 would appear to be on the verge of criticality, although they did not demonstrate a propensity for spread in the large scale tests.

The flammability parameters calculated on the basis of the combined data, shown in Fig. $4 c$, seem to yield predictions that are most consistent with the simplified model. All the fabrics that did not propagate flames in the large-scale tests have flammability parameters of less than -2.5 when calculated on this basis. The three fabrics that clearly demonstrated the propensity to propagate flames have flammability parameters between 0.6 and 2.3 on this basis. The results seem to demonstrate both the appropriate distinctions between fabrics that propagate flames and those that burn out locally as well as approximately correct absolute values for the flammability parameter. Thus, this method of evaluation would appear useful for screening purposes, although more data and comparisons with large-scale room/corner fire tests will be necessary to further evaluate the general validity of this approach.

The large-scale heat release rate of the Fabric $Q$ two-foot test specimen warrants discussion. Belles, et al., [15] noted that changes in adhesives and substrates could produce more than two-fold differences in peak heat release rates for the same fabric. When tested in one-foot widths, Fabric Q produced a peak heat release rate of $207 \mathrm{~kW}$. When tested in a fully-lined room, Fabric Q produced a peak heat release rate of only $297 \mathrm{~kW}$. Yet, when tested in three tests using two-foot widths, Fabric Q produced peak heat release rates of 497,474 and $928 \mathrm{~kW}$, respectively. The primary reason for this range of behavior is believed to be changes in the adhesive and the application rate of the adhesive. Another factor of importance noted by Belles, et al., is the effect of sample conditioning before a test.

These factors demonstrate the importance of recreating in small-scale all the relevant factors that can affect large-scale performance. They also point up the importance of using application methods in the field that duplicate the methods used for qualification testing. While the reason for the apparently anomalous behavior of Fabric $Q$ cannot be traced to any one factor, the factors discussed here are likely to provide the basis for it. For the present, the validity of the two-foot Fabric $Q$ data point must be questioned. 


\section{SUMMARY AND CONCLUSIONS}

A simplified model of upward flame spread that considers fuel burnout has been applied to the evaluation of the flame propagation potential of thin fuels adhered to noncombustible substrates. The method uses data derived from small-scale heat release rate measurements in the Cone Calorimeter at two imposed heat fluxes, 30 and 50 $\mathrm{kW} / \mathrm{m}^{2}$. These data are used to calculate a flammability parameter $\left(\mathrm{kE} \dot{\mathrm{E}}^{n-}-\mathrm{t}_{\mathrm{f}} / \mathrm{t}_{\mathrm{bo}}\right)$. The value of the flammability parameter depends on the imposed heat flux.

The simplified flame spread theory incorporates a number of linearizations to permit the development of an approximate analytical solution. These simplifications include those related to the flame length, the imposed heat flux at the fuel surface, the unit heat release rate history and the fuel burning duration. Despite these approximations, the simplified theory seems to yield screening evaluations that are consistent with large scale performance.

More data and further comparisons are needed to further validate the concepts presented here. The distinction between propagating and non-propagating materials illustrated in Fig. $4 a-c$ is encouraging, but data closer to the critical value of the flammability parameter would be useful to further test the method. For safety, however, the objective should be to develop products with flammability parameters well below the critical value. Fabric G seems to exemplify this desirable behavior.

The flammability parameter developed here assumes that the flame spread time defined in Equation 2 is the time required to raise the fuel surface from ambient to the ignition temperature. If significant preheating of the fuel occurs, as for example a ceiling immersed in a hot gas layer, then this temperature difference diminishes, the flame spread time decreases and the flammability parameter increases, perhaps past the critical value. From the standpoint of the methodology presented here, the potential for significant fuel preheating from an exposure fire should be addressed. Where such potential exists, more sophisticated and detailed analytical tools may be warranted, particularly for materials with flammability parameters near the critical value.

\section{NOMENCLATURE}

$\begin{array}{ll}\mathrm{E} & \text { Energy release }(\mathrm{kJ}) \\ \mathrm{E} & \text { Energy release rate }(\mathrm{kW}) \\ \mathrm{k} \rho \mathrm{c} & \text { Thermal inertia }\left[\left(\mathrm{kW} / \mathrm{m}^{2}-\mathrm{K}\right)^{2}-\mathrm{s}\right] \\ \mathrm{k} & \text { Flame length parameter } \\ \mathrm{m} & \text { Mass }(\mathrm{kg}) \\ \dot{\mathrm{q}} " & \text { Heat flux }\left(\mathrm{kW} / \mathrm{m}^{2}\right) \\ \mathrm{t} & \text { Time }(\mathrm{s}) \\ \mathrm{T} & \text { Temperature }(\mathrm{K} \text { or } \mathrm{C}) \\ \mathrm{V} & \text { Velocity }(\mathrm{m} / \mathrm{s}) \\ \mathrm{x} & \text { Length parameter }(\mathrm{m})\end{array}$

\section{Subscripts}

$\begin{array}{ll}\text { b } & \text { Burnout zone } \\ \text { bo } & \text { Burning duration } \\ \text { e } & \text { External } \\ \text { f } & \text { Flame zone } \\ \text { ig } & \text { Ignition } \\ \text { p } & \text { Pyrolysis zone } \\ \text { s } & \text { Surface }\end{array}$

\section{Superscripts}

$$
\begin{aligned}
& \text { Time rate of change }\left(\mathrm{s}^{-1}\right) \\
& \text { Per unit length }\left(\mathrm{m}^{-1}\right) \\
& \text { Per unit area }\left(\mathrm{m}^{-2}\right)
\end{aligned}
$$




\section{REFERENCES}

1. Currently, there are three model building codes in the United States. These include the Uniform Building Code published by the International Conference of Building Officials, the National Building Code published by the Building Officials and Code Administrators, International, and the Standard Building Code published by the Southern Building Code Congress International.

2. "Test for Surface Burning Characteristics of Building Materials (ASTM E84)," Annual Book of ASTM Standards, Part 18, American Society for Testing and Materials, Philadelphia, PA, 1984.

3. Quintiere, J., Harkleroad, M., and Hasemi, Y., "Wall Flames and Implications for Upward Flame Spread," Combustion Science and Technology, Vol. 48, pp. 191-222, 1986.

4. Carslaw, H.S. and Jaeger, J.C., Conduction of Heat in Solids, 2nd Edition, Oxford University Press, 1959.

5. Williamson, R.B., Revenaugh, A., and Mowrer, F.W., "Ignition Sources in Room Fire Tests and Some Implications for Flame Spread Evaluation," to appear in the Third International Symposium on Fire Safety Science.

6. Hasemi, Y., "Experimental Wall Flame Heat Transfer Correlations for the Analysis of Upward Flame Spread," Fire Science and Technology, Vol. 4, No. 2, 1984, p. 75.

7. Saito, K., Quintiere, J.G., and Williams, F.A., "Upward Turbulent Flame Spread," Fire Safety Science - Proceedings of the First International Symposium, pp. 75-86, 1986.

8. Cleary, M. and Quintiere, J.G., "A Framework for Utilizing Fire Property Tests," to appear in the Third International Symposium on Fire Safety Science.

9. "Standard Test Method for Heat and Visible Smoke Release Rates for Materials and Products Using an Oxygen Consumption Calorimeter (E 1354-90)," Annual Book of ASTM Standards, American Society for Testing and Materials, Philadelphia, PA, 1990.

10. Harkleroad, M., "Fire Properties Database for Textile Wall Coverings," NISTIR 894065, National Institute of Standards and Technology, Gaithersburg, MD, March 1989.

11. Fisher, F.L., MacCracken, W., and Williamson, R.B., "Room Fire Experiments of Textile Wall Coverings - A Final Report of all Materials Tested Between March 1985 and January 1986," Service to Industry Report No. 86-2, Fire Research Laboratory, University of California, Berkeley, California, March 1986.

12. Belles, D.W., Fisher, F.L., and Williamson, R.B., "How Well Does ASTM E84 Predict the Fire Performance of Textile Wallcoverings?", Fire Journal, Vol. 82, No. 1, 1988, pp. 24-30,74. 